\title{
Nanoparticles of TiAlZr mixed oxides as supports of hydrodesulfurization catalysts: Synthesis and characterization
}

\author{
E. Kraleva ${ }^{\mathrm{a}, *}$, A. Spojakina ${ }^{\mathrm{b}}$, M.L. Saladino $^{c}$, E. Caponetti $^{\mathrm{c}, \mathrm{d}}, \mathrm{G}$. Nasillo $^{\mathrm{d}}$, K. Jiratova $^{\mathrm{e}}$ \\ a Institute of Biodiversity and Ecosystems Research, Bulgarian Academy of Sciences, Sofia, Gagarin st.2, Bulgaria \\ ${ }^{\mathrm{b}}$ Institute of Catalysis, Bulgarian Academy of Sciences, 1113 Sofia, Bulgaria \\ ' Dipartimento di Chimica “S. Cannizzaro", Università di Palermo and INSTM-Udr Palermo, Parco d'Orleans II Viale delle Scienze pad 17, I-90128 Palermo,Italy \\ d Centro Grandi Apparecchiature - UniNetLab, Università di Palermo, Via F. Marini 14, I-90128 Palermo, Italy \\ e Institute of Chemical Process Fundamentals, 16502 Prague 6, Czech Republic
}

\section{A R T I C L E I N F O}

\section{Article history:}

Received 1 September 2011

Received in revised form 6 October 2011

Accepted 7 October 2011

Available online 24 October 2011

\section{Keywords:}

Mixed oxides supports

Sol-gel process

Co-Mo-P-catalysts

Thiophene hydrodesulfurization

\begin{abstract}
A B S T R A C T
TiAlzr mixed oxides, synthesized using sol-gel method, were characterized and used as supports of hydrodesulfurization catalysts ( $12 \mathrm{wt} \% \mathrm{Mo}$ ) prepared by impregnation either with molybdenum heteropolyacid $\mathrm{H}_{3} \mathrm{PMo}_{12} \mathrm{O}_{40}$ or its cobalt salt $\mathrm{Co}_{1.5} \mathrm{PMo}_{12} \mathrm{O}_{40}$. Structure, morphology and textural properties of oxides and catalysts were characterized using X-ray powder diffraction (XRD), Raman spectroscopy, Nitrogen adsorption porosimetry, TEM-EDS, temperature-programmed desorption (TPD) and temperature-programmed reduction (TPR) techniques. Activity of the catalytic systems was tested in thiophene hydrodesulfurization (HDS).

No formation of a new oxide phase was revealed in the synthesized mixed materials. However the effect of separated oxides on the structure of ternary oxides was observed. Maximum in HDS activity of Mo containing samples was determined by optimum content of alumina in the mixed oxides. Incorporation of cobalt into the heteropolyacid increased the HDS activity about two times and masked the effect of the support composition.
\end{abstract}

(C) 2011 Elsevier B.V. All rights reserved.

\section{Introduction}

During the last years, supported molybdenum oxide catalysts have been object of great interest because of their importance in environmental catalysis and in many industrial reactions such as hydrodesulfuration (HDS) [1-8]. These catalysts are normally obtained by impregnating the catalytically active molybdenum oxide species on an inorganic oxide support $\left(\mathrm{Al}_{2} \mathrm{O}_{3}, \mathrm{SiO}_{2}, \mathrm{TiO}_{2}\right.$, and $\mathrm{ZrO}_{2}$ ) for the purpose of (1) increasing the catalytic activity and selectivity, (2) extending the life of the catalysts, and (3) augmenting the mechanical strength of the catalysts. Now it is established in the literature that the structure of the dispersed molybdenum species is closely related to the nature of the specific oxide support, the loading amount, the preparation procedure, and the calcination temperature [8]. It is also well known that the catalytic performances of supported catalysts depend, to a certain extent, on the support used. The support can affect following catalyst properties: (i) improvement of the dispersion of the active phase; (ii) decreasing of the formation of the inactive phases; (iii) modification of the reducibility of the oxide precursors through

\footnotetext{
* Corresponding author. Tel.: +359 885450982.

E-mail address: ekraleva@gmail.com (E. Kraleva).
}

change of the interaction between the active phase and support, and (iv) reducing of the deactivation due to the coke formation. The efficiency of the supported catalysts is strongly related to the amount and dispersion of the active phase, which can be influenced by nature and preparation method of the support oxide as well as by the calcinations temperature of the catalytic materials $[8,9]$. Several models have been proposed to explain the dispersed state of molybdena on various single oxides supports [8]. The models can be divided into two categories: the first model suggests that under appropriate conditions a monolayer of the dispersed ionic compound is formed on the surface of the support. The second model proposes that instead of forming an overlapping monolayer, the dispersed metal cations be incorporated into the surface vacant sites of the support with their accompanying anions staying on top of them for charge compensation. However, the main disadvantage of single oxide supports is their typical small surface area in addition to the intrinsic nature of phase transformation at high temperature [10]. The combination of different oxides can minimize the particle sintering, improve mechanical properties and increase the surface area. In order to overcome these drawbacks, increasing attention has been focused to the development of mixed oxide supports by combining higher surface areas and thermal stability of alumina and silica with the unique acidic properties of $\mathrm{ZrO}_{2}$ and $\mathrm{TiO}_{2}$ [11-13]. Various mixed oxides $\left(\mathrm{TiO}_{2}-\mathrm{SiO}_{2}, \mathrm{TiO}_{2}-\mathrm{ZrO}_{2}\right.$, 
$\mathrm{SiO}_{2}-\mathrm{ZrO}_{2}, \mathrm{TiO}_{2}-\mathrm{Al}_{2} \mathrm{O}_{3}$ ) have been already studied [14-17] in many industrial reactions such as hydrodesulfuration [18-22].

Different techniques such as mechanical mixing of the component oxides, co-precipitation of alkoxide precursors, sol-gel synthesis, etc., were used for the preparation of mixed oxides. Sol-gel techniques are promising for synthesizing catalytic materials with a homogeneous distribution of components. The textural properties of the mixed oxides, such as pore size distribution, surface area, etc., are strongly dependent upon synthesis conditions, the nature and composition of the alkoxide precursors, solvent, complexing/templating agent, hydrolysis, and gelation conditions. Sol-gel synthesis of mixed oxides generally involves the acid or base hydrolysis of the component alkoxide precursors in the presence or absence of a complexing (templating) agent, gelation by condensation, polymerization and drying, followed by calcination at higher temperatures to burn off the organics. However, only few authors reported the preparation of ternary oxides [23-27].

The aim of this paper is to synthesize ternary mixed TiAlZr oxides, to study behavior of the individual oxides in the phase formation, to examine their peculiarities, and to use them as supports of the HDS catalysts prepared by impregnation with molybdenum heteropolyacid and its Co salt.

\section{Experimental}

\subsection{Materials}

$\mathrm{Zr}\left(\mathrm{OCH}_{2} \mathrm{CH}_{2} \mathrm{CH}_{3}\right)_{4}$ (zirconium(IV) propoxide, Aldrich), Ti( $\left.\mathrm{OCH}_{2} \mathrm{CH}_{2} \mathrm{CH}_{3}\right)_{4}$ (titanium(IV) propoxide, Aldrich), and $\left[\mathrm{C}_{2} \mathrm{H}_{5} \mathrm{CH}\left(\mathrm{CH}_{3}\right) \mathrm{O}\right]_{3} \mathrm{Al}$ (aluminum tri-sec-butoxide, Aldrich) were the sources of $\mathrm{Zr}^{4+}, \mathrm{Ti}^{4+}$ and $\mathrm{Al}^{3+}$ ions. $\mathrm{CH}_{3} \mathrm{CH}_{2} \mathrm{CH}_{2} \mathrm{OH}$ (1propanol, Merck) and $\mathrm{NH}_{4} \mathrm{OH}$ (ammonia solution, Merck) were used as received. $\mathrm{H}_{3} \mathrm{PMo}_{12} \mathrm{O}_{40} \cdot n \mathrm{H}_{2} \mathrm{O}$ (molybdenum heteropolyacid, Fluka) and $\mathrm{Co}_{1.5} \mathrm{PMo}_{12} \mathrm{O}_{40}$ salt (prepared after M.T. Pope [28]) were used as active components for catalytic systems. Solutions were prepared by weight adding conductivity grade water.

\subsection{Supports and catalysts preparation}

Ternary TiAlZr oxides containing 20 and 38 wt\% of $\mathrm{Al}_{2} \mathrm{O}_{3}$ in the samples (corresponding to 16.4 and $39.3 \mathrm{~mol} \%$, see Table 1 ) were prepared by sol-gel method using alkoxides as precursors: $\mathrm{Ti}\left(\mathrm{OCH}_{2} \mathrm{CH}_{2} \mathrm{CH}_{3}\right)_{4}$ and $\mathrm{Zr}\left(\mathrm{OCH}_{2} \mathrm{CH}_{2} \mathrm{CH}_{3}\right)_{4}$ were mixed at appropriate composition in 1-propanol at $18^{\circ} \mathrm{C}$ under constant stirring. After that, $\left[\mathrm{C}_{2} \mathrm{H}_{5} \mathrm{CH}\left(\mathrm{CH}_{3}\right) \mathrm{O}\right]_{3} \mathrm{Al}$ was added under constant stirring until solution became homogeneous $(\sim 0.5 \mathrm{~h})$. Then, $\mathrm{NH}_{4} \mathrm{OH}$ was added $(\mathrm{pH} 9)$ and the solution was stirred for $5 \mathrm{~min}$. At this stage, the molar ratio of the components of the reaction was following: Alkoxides: $\mathrm{CH}_{3} \mathrm{CH}_{2} \mathrm{CH}_{2} \mathrm{OH}: \mathrm{H}_{2} \mathrm{O}: \mathrm{NH}_{4} \mathrm{OH}=1: 4: 4: 0.33$. Then temperature was increased to $30^{\circ} \mathrm{C}$ and, after $10 \mathrm{~min}$ at reflux temperature $\left(18^{\circ} \mathrm{C}\right)$ deionized water was added drop by drop to complete hydrolysis and reflux was continued for $1 \mathrm{~h}$. The resulted mixture was cooled to room temperature. The gels were aged in situ for $24 \mathrm{~h}$ and the residual liquid was removed after decanting. The powder was obtained after heating in an oven at $100^{\circ} \mathrm{C}$ for $24 \mathrm{~h}$. Then, the samples were treated at $550{ }^{\circ} \mathrm{C}$ for $5 \mathrm{~h}$ in static air. The label of the support with lower amount of $\mathrm{Al}_{2} \mathrm{O}_{3}$ is TiAlZr-1 and the label of the second support is TiAlZr-2. Composition of the samples is shown in Table 1.

As reference, binary oxides $\mathrm{TiO}_{2}-\mathrm{Al}_{2} \mathrm{O}_{3}$ with $20 \mathrm{wt} \%$ of $\mathrm{Al}_{2} \mathrm{O}_{3}$ (corresponding to $13.5 \mathrm{~mol} \%$ ) and $\mathrm{TiO}_{2}-\mathrm{ZrO}_{2}$ with $15.8 \mathrm{wt} \%$ of $\mathrm{ZrO}_{2}$ (corresponding to $26.4 \mathrm{~mol} \%$ ) in the samples were also prepared. The labels of the supports are TiAl20 and TiZr20. The procedure of their preparation was the same as that of the ternary oxides. The preparation method of the pure $\mathrm{TiO}_{2}$ and $\mathrm{ZrO}_{2}$ oxides, taken for comparison, is reported in our previous paper [16] and preparation of pure $\mathrm{Al}_{2} \mathrm{O}_{3}$ is mentioned in Ref. [29].

HDS catalysts were prepared by impregnation of the obtained supports with water solution of molybdenum heteropolyacid $\mathrm{H}_{3} \mathrm{PMo}_{12} \mathrm{O}_{40}$ or of its cobalt salt $\mathrm{Co}_{1.5} \mathrm{PMo}_{12} \mathrm{O}_{40}$. All catalysts were prepared with identical molybdenum concentration (12 wt\%). Amount of cobalt was fixed to $0.9 \mathrm{wt} \%$, as the Co:Mo molar ratio in the loaded $\mathrm{Co}_{1.5} \mathrm{PMo}_{12} \mathrm{O}_{40}$ salt is $1: 8$. The catalysts were dried $2 \mathrm{~h}$ at $120^{\circ} \mathrm{C}$ and calcined $4 \mathrm{~h}$ at $350^{\circ} \mathrm{C}$. The labels of the Mo catalysts are Mo/TiAl20, Mo/TiZr20, Mo/TiAlZr-1, Mo/TiAlZr-2, and those of CoMo catalysts are CoMo/TiAl20, CoMo/TiZr20, CoMo/TiAlZr-1, CoMo/TiAlZr-2.

\subsection{Characterization methods}

$X$-ray powder diffraction (XRD) patterns were recorded in $2 \theta$ range of 20-90 at steps of $0.05^{\circ}$ and counting time of $5 \mathrm{~s} / \mathrm{step}$ on a Philips PW 1050 diffractometer, equipped with a $\mathrm{Cu}$ tube and scintillation detector beam. The X-ray generator worked at $40 \mathrm{kV}$ and $30 \mathrm{~mA}$. The instrument resolution (divergent and antiscatter slits of $0.5^{\circ}$ ) was determined using standards free from the effect of reduced crystallite size and lattice defects.

Adsorption isotherms of nitrogen at $-196^{\circ} \mathrm{C}$ were measured with a Micromeritics ASAP 2020M instrument. Prior to the measurement, the samples were degassed overnight at $120^{\circ} \mathrm{C}$ and $0.1 \mathrm{~Pa}$. To guarantee the precision of the obtained data the purity of the used nitrogen (Technoplyn, Linde) was 99.9995\%.

High Resolution-Transmission Electron Microscopy (HR-TEM) study was performed using a JEM-2100 (JEOL, Japan) operating at $200 \mathrm{kV}$ accelerating voltage, equipped with an energy dispersive X-ray spectrometer (EDS) (Oxford, UK) suited for elemental identification. The powder in isopropanol was sonicated to ensure a homogeneous dispersion. A small drop was deposited on a 200 mesh carbon-coated copper grid, which was introduced into the TEM chamber analysis after complete solvent evaporation.

Raman spectra were obtained using a single Raman spectrometer LabRAM HR Visible, equipped with a microscope Olympus BX41, edge filters and Peltier-cooled CCD detector. The $633 \mathrm{~nm}$ He-Ne laser line was used for excitation. A 50× objective was used to focus the incident laser beam onto a spot of about $3 \mu \mathrm{m}$ in diameter and to collect the scattered light in a backscattering geometry. The laser power applied on the spot was $9 \mathrm{~mW}$. Preceding tests with laser power confirmed no local overheating of the sample under the conditions used.

Temperature-programmed desorption (TPD) of $\mathrm{NH}_{3}$ was carried out to examine acid properties of the catalysts surface. The measurements were accomplished with $0.050 \mathrm{~g}$ of a sample in the temperature range of $20-1000^{\circ} \mathrm{C}$, with helium as a carrier gas and $\mathrm{NH}_{3}$ as an adsorbing gas. Prior to the measurement, each sample was calcined in helium to $350^{\circ} \mathrm{C}$, then cooled to $30^{\circ} \mathrm{C}$ and an excess of ammonia (10 doses, each $840 \mu \mathrm{l}$ ) was applied on the sample. Then, the sample was flushed with helium for $1 \mathrm{~h}$ to remove physically adsorbed ammonia. The heating rate $20^{\circ} \mathrm{C} / \mathrm{min}$ was applied and a change in ammonia concentration of the gas mixture was registered by a mass spectrometer Omnistar 200, Balzers. During the experiments the following mass contributions $m / z$ were collected: $2-\mathrm{H}_{2}, 18-\mathrm{H}_{2} \mathrm{O}$, and $16-\mathrm{NH}_{3}$. The spectrometer was calibrated by dosing the known amount of $\mathrm{NH}_{3}(840 \mu \mathrm{l})$ into the carrier gas $(\mathrm{He})$ in each experiment to obtain quantitative desorption data.

Temperature-programmed reduction (TPR) measurements of the calcined samples $(0.025 \mathrm{~g})$ were performed with a $\mathrm{H}_{2} / \mathrm{N}_{2}$ mixture $\left(10 \mathrm{~mol} \% \mathrm{H}_{2}\right)$, flow rate $50 \mathrm{ml} \mathrm{min}^{-1}$ and linear temperature increase $20^{\circ} \mathrm{C} / \mathrm{min}$ up to $1000^{\circ} \mathrm{C}$. A change in $\mathrm{H}_{2}$ concentration was detected with a catharometer. Reduction of the grained $\mathrm{CuO}$ $(0.16-0.315 \mathrm{~mm})$ was employed to calibrate the catharometer response.

\subsection{Catalytic test}

The HDS activity of obtained catalysts was evaluated in a continuous flow reactor at $0.1 \mathrm{MPa}$ and $350^{\circ} \mathrm{C}$. Each experiment was carried out with a catalyst sample $(0.1 \mathrm{~g})$ which was standardized by in situ heating $(30 \mathrm{~min})$ at $350^{\circ} \mathrm{C}$ in $\operatorname{argon}$. The catalyst was activated by sulfidation with a mixture of $\mathrm{H}_{2} \mathrm{~S}+\mathrm{H}_{2}(1: 10)$ at $350{ }^{\circ} \mathrm{C}$ for $1 \mathrm{~h}$ and flow rate $40 \mathrm{~cm}^{3} \mathrm{~min}^{-1}$. We have found out in our preliminary experiments that this sulfidation treatment gives maximum thiophene conversion with our catalyst [30]. When the activation of the catalyst was completed, the catalyst was flushed (30 min) with argon at the same temperature, and then, and then, the reaction mixture $(6 \mathrm{~mol} \%$ of thiophene in hydrogen prepared separately by mixing of thiophene with hydrogen (thiophene was continuously added to hydrogen by means of a dosing device) and resulting reaction mixture was fed into the reactor in order WHSV of thiophene was $2 \mathrm{~h}^{-1}$. Reaction products (thiophene, tetrahydrothiophene and a mixture of $C 4$ hydrocarbons) were analyzed by a gas chromatograph. Accuracy of the measurements were \pm 5 relative $\%$. Activity of the catalyst, expressed as the thiophene conversion to hydrocarbons $\left(C_{4}\right)$, had been measured for $5 \mathrm{~h}$.

\section{Results and discussion}

\subsection{Structure, morphology and textural properties of samples}

Powder XRD patterns of all prepared samples, the supports (single $\mathrm{Al}_{2} \mathrm{O}_{3}, \mathrm{TiO}_{2}, \mathrm{ZrO}_{2}$ oxides, binary and ternary TiAl20, TiAlZr-1, TiAlZr-2, TiZr20 oxides), and molybdenum and CoMo catalysts are shown in Fig. 1A-C.

The X-ray diffractograms of the supports, pure $\mathrm{TiO}_{2}, \mathrm{ZrO}_{2}, \mathrm{Al}_{2} \mathrm{O}_{3}$ and mixed oxides are presented in Fig. 1A. Only anatase phase of titania was observed in $\mathrm{TiO}_{2}$ and $\mathrm{TiAl} 20$ mixed oxides [16]. Zirconia consisted of a mixture of tetragonal and monoclinic phase in the $76: 24 \mathrm{wt} \%$ proportions, whereas in the alumina support only $\gamma-\mathrm{Al}_{2} \mathrm{O}_{3}$ was revealed [29]. Diffraction patterns of the ternary oxides, TiAlZr-1 and TiAlZr-2, show presence of amorphous phase only. In the case of ternary TiAlZr oxides (1:1:1 molar ratio) other researchers [5] also report presence of amorphous phase only and state that the addition of zirconia promotes amorphization of the mixed oxides. 
Table 1

Chemical composition of the supports.

\begin{tabular}{|c|c|c|c|c|c|c|c|}
\hline \multirow[t]{2}{*}{ Support } & \multicolumn{3}{|l|}{ wt\% } & \multicolumn{3}{|c|}{$\mathrm{mol} \%$} & \multirow{2}{*}{$\begin{array}{l}\text { Molar ratio } \\
\mathrm{TiO}_{2}: \mathrm{Al}_{2} \mathrm{O}_{3}: \mathrm{ZrO}_{2}\end{array}$} \\
\hline & $\mathrm{TiO}_{2}$ & $\mathrm{Al}_{2} \mathrm{O}_{3}$ & $\mathrm{ZrO}_{2}$ & $\mathrm{TiO}_{2}$ & $\mathrm{Al}_{2} \mathrm{O}_{3}$ & $\mathrm{ZrO}_{2}$ & \\
\hline TiAl20 & 80 & 20 & 0 & 86 & 13.5 & 0 & 1:0.58:0 \\
\hline TiAlZr-1 & 40 & 20 & 40 & 52.4 & 16.4 & 31.2 & $1: 1.16: 1.92$ \\
\hline TiAlZr-2 & 33.1 & 38.2 & 28.7 & 45 & 39.3 & 26.9 & $1: 2.67: 1.66$ \\
\hline TiZr20 & 84.2 & 0 & 15.8 & 73.6 & 0 & 15.8 & $1: 0: 0.36$ \\
\hline
\end{tabular}

The XRD patterns of the TiAl20 mixed oxide and of corresponding catalysts prepared by impregnation with HPMo acid or its Co salt are reported in Fig. 1B. Anatase was the only phase revealed in all samples. The absence of the XRD peaks ascribed to the crystalline HPMo phase indicates decomposition of the acid with subsequent formation of amorphous or well-dispersed molybdenum phase. The XRD patterns of the Mo and CoMo catalysts prepared on the ternary TiAlZr oxides containing different amount of alumina are reported in Fig. 1C. The patterns show similar amorphous structure as that of the catalysts prepared on binary oxides, confirming high dispersion of the species formed on the catalyst surfaces. Analogous results were observed by Ulín et al. [31].

The Raman spectra of the supports are shown in Fig. 2A and those of the Mo and CoMo catalysts are depicted in Fig. 2B. This figure also shows the detailed Raman spectra (from 600 to $1200 \mathrm{~cm}^{-1}$ ) of the catalysts supported over ternary TiAlZr oxides (in the inset).

Raman spectrum of $\mathrm{TiO}_{2}$ exhibited bands at 144, 199, 397, 518, and $638 \mathrm{~cm}^{-1}$, characteristic of the anatase phase, and the spectrum of $\mathrm{Al}_{2} \mathrm{O}_{3}$ a band at $480 \mathrm{~cm}^{-1}$. The spectrum of $\mathrm{ZrO}_{2}$ displays bands at $181,190,222,310,337,382,474,499,540,559,620$, and $636 \mathrm{~cm}^{-1}$ characteristic of the monoclinic phase. The Raman spectrum of the mixed oxide TiAl20 contains only broad bands at 144 , 397,518 , and $638 \mathrm{~cm}^{-1}$ characteristic of the anatase phase. The spectra of TiAlZr-1 and TiAlZr-2 show bands of the anatase phase together with the band at $480 \mathrm{~cm}^{-1}$, characteristic of $\mathrm{Al}_{2} \mathrm{O}_{3}$. The anatase crystallites in the ternary mixed oxides can be formed by faster hydrolysis rate of titanium alkoxide than that of zirconia or alumina alkoxides. When two or more alkoxides are hydrolyzed prior their mixing, large clusters of individual components will be formed. Therefore, it is preferable to hydrolyze all alkoxides after their dissolving in a solvent and mixing. Such procedure leads to the chemical modification due to $\mathrm{M}_{1}-\mathrm{O}-\mathrm{M}_{2}$ bond formation. In some cases, one component may be more reactive than the other, leading to segregation of one of the oxides [32].
Raman spectra of the prepared catalysts are presented in Fig. 2B. In the spectrum of Mo/TiAl20, the bands at about 150, 400, 540, 670, and $950 \mathrm{~cm}^{-1}$, characteristic of anatase, are shown. No bands of the molybdophosphoric anion appearing at 991, 971, 909, 607 and $250 \mathrm{~cm}^{-1}$ [33] are observed in the spectra probably due to the interaction of the anion with the support. The spectrum of CoMo/TiAl20 is nearly identical though the band observed at $150 \mathrm{~cm}^{-1}$ is shifted to $175 \mathrm{~cm}^{-1}$ indicating formation of a bond between cobalt and Ti-OH group. The shoulder of the ca. $210 \mathrm{~cm}^{-1}$ band observed in the sample with loaded HPMo acid could indicate the presence of a weak Mo-O-P bond (analogous peak was found at $246-244 \mathrm{~cm}^{-1}$ in the initial HPMo acid [34]).

Examining spectra of the supported HPMo catalysts over ternary mixed oxides, characteristic bands at 758,840 , and $945 \mathrm{~cm}^{-1}$, with very small deviations, are noticed; such spectrum is usually considered to be characteristic of the so-called polymolybdate phase. These bands can be assigned to both Mo- $\mathrm{O}_{\mathrm{d}}$ bond shifts to lower wavelength and formation of a bridge $\mathrm{Mo}_{-} \mathrm{O}_{\mathrm{c}}-\mathrm{Mo}$ bond. In the CoMo catalysts supported over the ternary oxides, low intensity bands at about $997-1000 \mathrm{~cm}^{-1}, 918 \mathrm{~cm}^{-1}$ and $596-601 \mathrm{~cm}^{-1}$, characteristic of $\mathrm{Mo}-\mathrm{O}_{\mathrm{d}}$ bond, bridge $\mathrm{Mo}-\mathrm{O}_{\mathrm{b}}-\mathrm{Mo}$ bond and very poorly resolved $\mathrm{Mo}-\mathrm{O}_{\mathrm{c}}-\mathrm{Mo}$ bonds in the heteropolyanion, respectively, are observed. The Raman spectra of the CoMo catalysts show the bands at 925 and $998 \mathrm{~cm}^{-1}$ that appear due to some contributions from Mo-O-Co stretching vibrations in $\mathrm{CoMoO}_{4}$ and $\mathrm{MoO}_{3}$ species [34,35]. Cobalt salt of HPMo acid increases the support amorphization that is more pronounced in the case of the TiAlZr-2 support containing higher amount of alumina.

Porous structure of the samples was carefully analyzed because the preparation of metal oxides by sol-gel methods leads very often to the formation of mesoporous and microporous materials. $\mathrm{N}_{2}$ physisorption was applied to determine the textural parameters of the examined materials. The obtained results are summarized in Table 2. Although the use of classic (two-parameter) BET equation
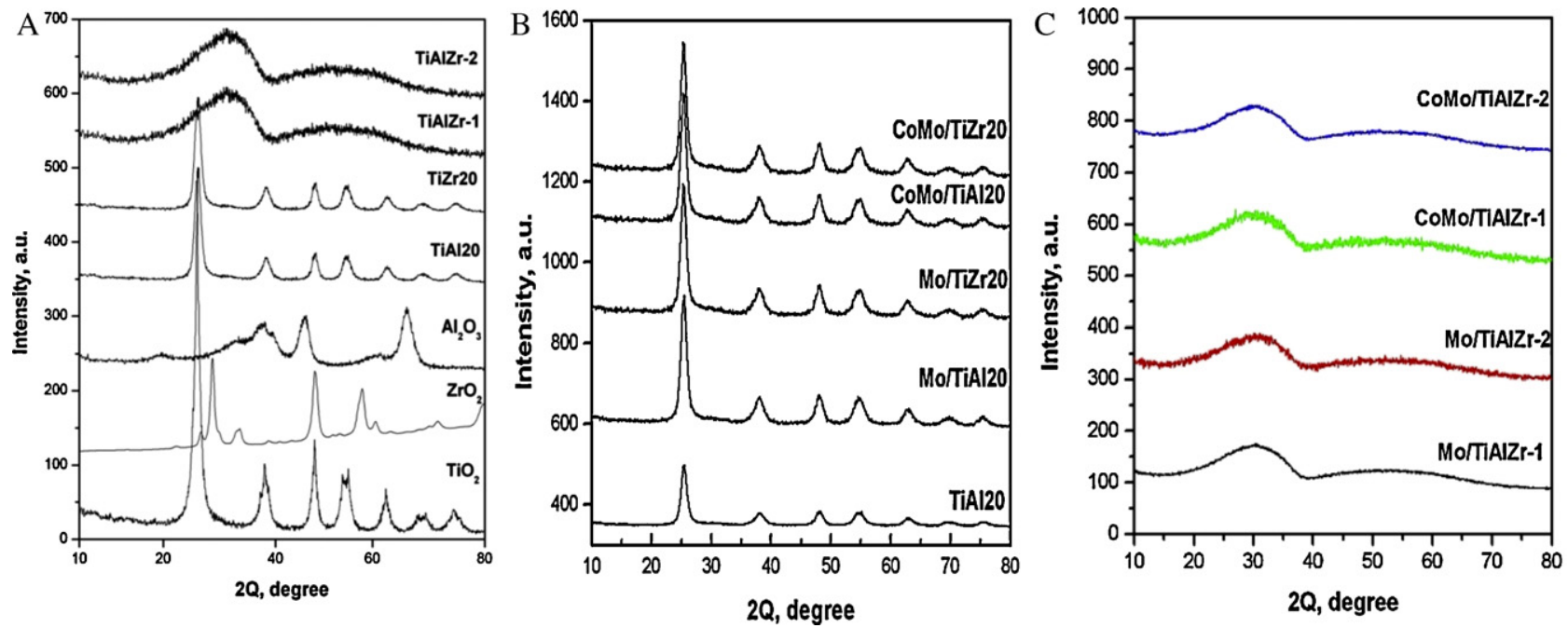

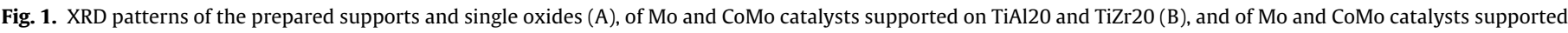
on ternary mixed oxides $(C)$. 

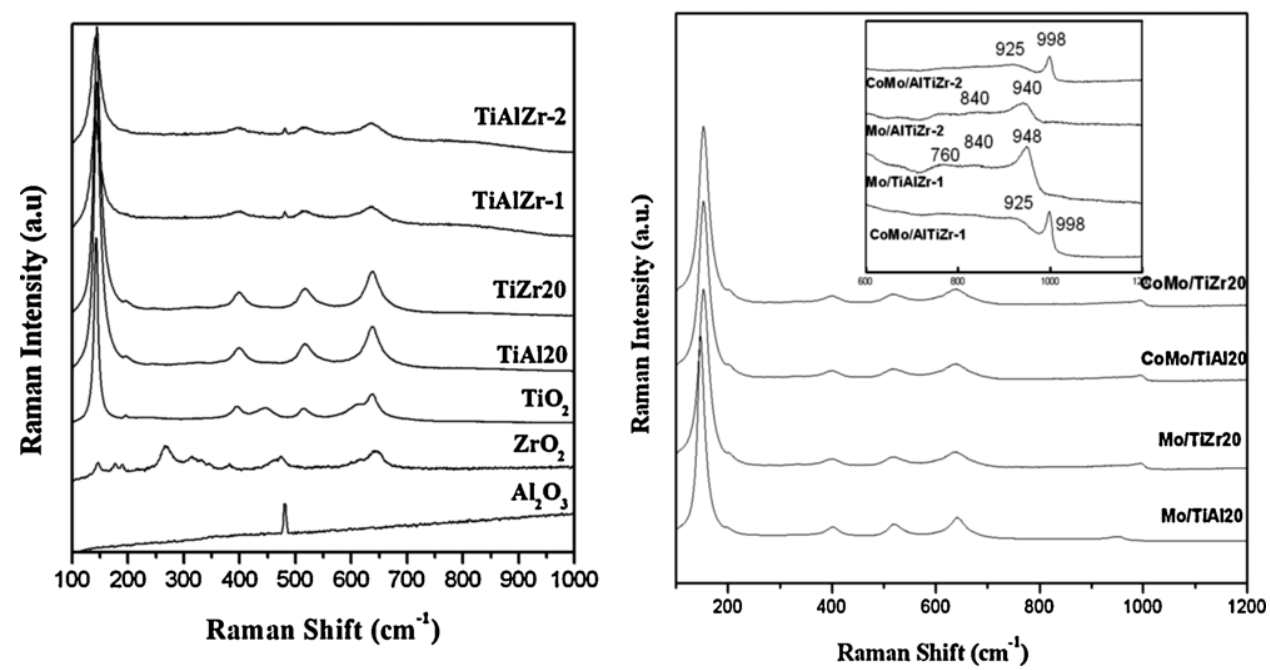

Fig. 2. Raman spectra of supports (A) and catalysts (B).

Table 2

Porous structure parameters of the supports and catalysts.

\begin{tabular}{|c|c|c|c|c|c|}
\hline Sample & $V_{\text {micro }}\left(\mathrm{mm}^{3} / \mathrm{g}\right)$ & $S_{\text {BET }}\left(\mathrm{m}^{2} / \mathrm{g}\right)$ & $S_{\text {meso }}\left(\mathrm{m}^{2} / \mathrm{g}\right)$ & $V_{\text {tot }}{ }^{\mathrm{a}}\left(\mathrm{cm}^{3} / \mathrm{g}\right)$ & $D(\mathrm{Nm})$ \\
\hline TiAl20 & 35 & 150 & 93 & 0.67 & 12.9 \\
\hline Mo/TiAl20 & 30 & 127 & 76 & 0.60 & 14.7 \\
\hline CoMo/TiAl20 & 27 & 114 & 66 & 0.43 & 11.6 \\
\hline TiAlZr-1 & 69 & 309 & 204 & 0.75 & 7.3 \\
\hline Mo/TiAlZr-1 & 42 & 214 & 150 & 0.52 & 6.9 \\
\hline CoMo/TiAlZr-1 & 43 & 225 & 154 & 0.60 & 7.4 \\
\hline TiAlZr-2 & 66 & 305 & 210 & 0.93 & 8.3 \\
\hline Mo/TiAlZr-2 & 59 & 257 & 159 & 0.66 & 7.7 \\
\hline CoMo/TiAlZr-2 & 49 & 229 & 144 & 0.70 & 8.5 \\
\hline TiZr20 & 38 & 172 & 90 & 0.68 & 13.5 \\
\hline Mo/TiZr20 & 32 & 138 & 78 & 0.62 & 16.2 \\
\hline CoMo/TiZr20 & 29 & 121 & 65 & 0.45 & 12.2 \\
\hline
\end{tabular}

$\mathrm{D}$ - Adsorption average pore width $\left(4 \mathrm{~V} / \mathrm{S}_{\mathrm{BET}}\right)$.

a $\mathrm{BJH}$ Adsorption cumulative volume of mesopores between $0.85 \mathrm{~nm}$ and $150 \mathrm{~nm}$ radius.

for the analysis of micro-mesoporous materials is not correct [36], the surface area $S_{\mathrm{BET}}$ is also included in the table for comparison with literature data. The nitrogen adsorption-desorption isotherms recorded at $-196^{\circ} \mathrm{C}$ are depicted in Fig. 3 .

Nitrogen isotherms of the supports and catalysts are similar and correspond to the combination of II type of isotherms according to IUPAC classification [37]. Micropore volume $V_{\text {micro }}$ of the individual samples were revealed from corresponding t-plots constructed according to Lecloux and Pirard [38]. A small increase in the adsorbed amount of nitrogen at $x=p / p_{0} \rightarrow 0$ is in accord with the presence of micropores in the samples. Mesopore surface areas of the tested materials were evaluated using the more precise threeparameter BET equation [38] and pore diameter $D$ was determined from the mesopore-size distribution evaluated according to the advanced Barrett, Joyner and Halenda (BJH) approach $[39,40]$ from the adsorption branch of the adsorption isotherm.
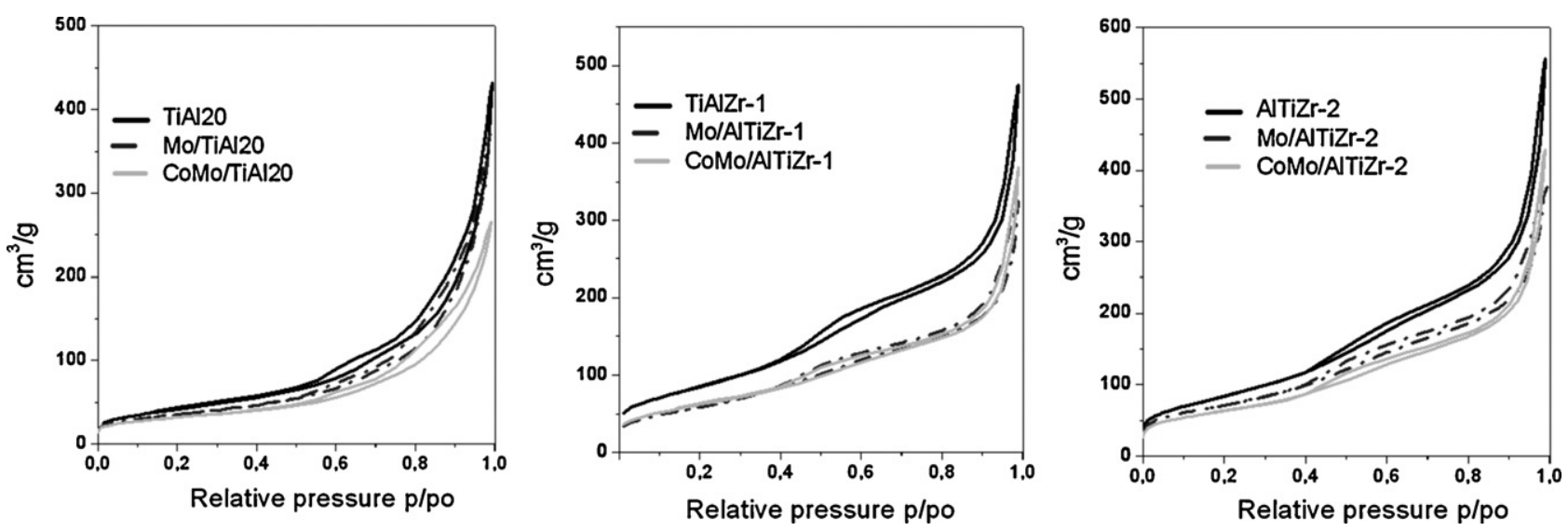

Fig. 3. Nitrogen isotherms of supports and catalysts. 

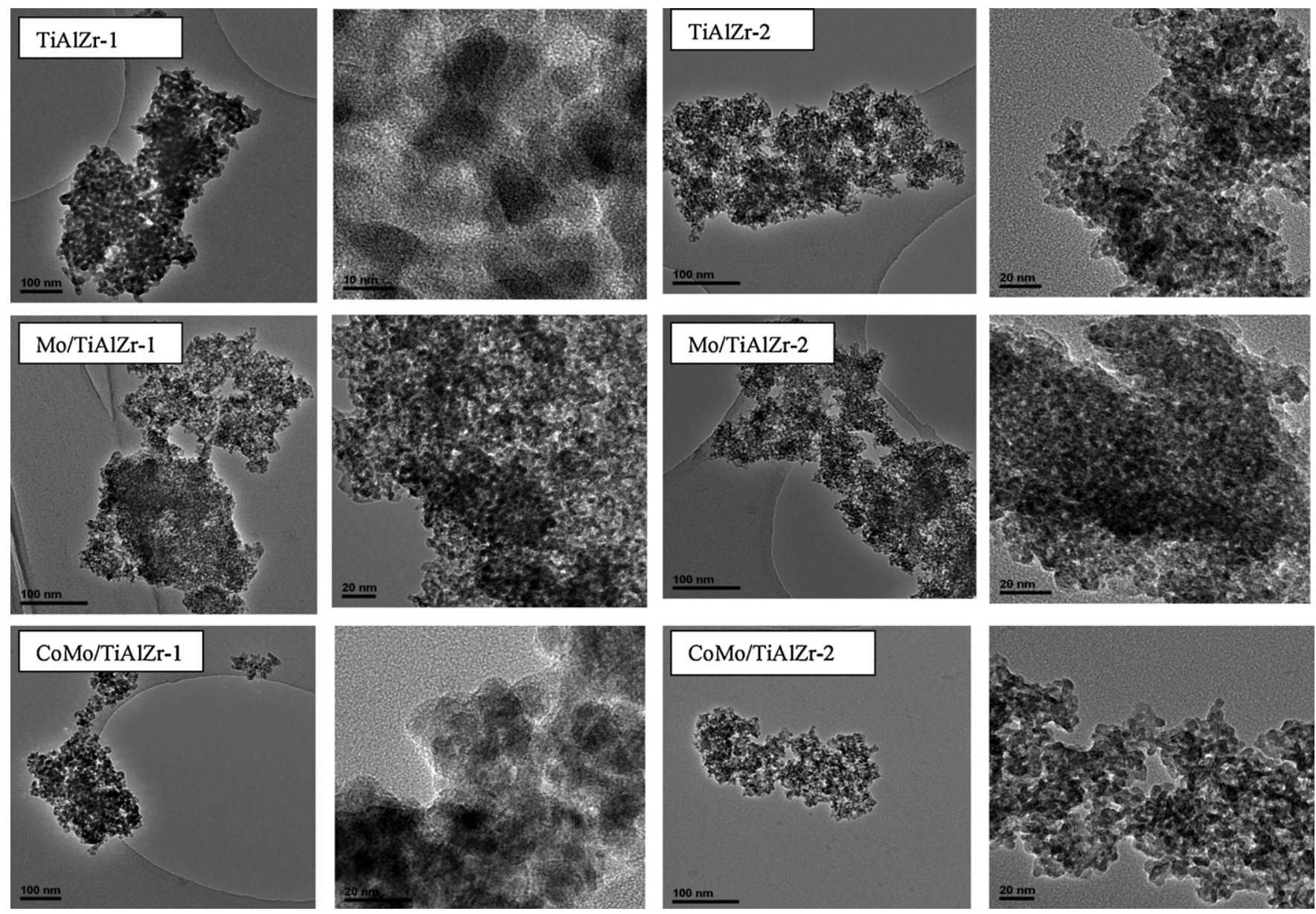

Fig. 4. HR-TEM micrographs of supports and catalysts at various magnifications.

The isotherms do not show great hysteresis loop. All prepared materials exhibit $\mathrm{H} 1$ type of hysteresis, characteristic of the solids consisting of particles crossed by nearly cylindrical channels or constituted by aggregates (consolidated) or agglomerates (unconsolidated) of spheroidal particles [41].

Table 2 documents that all samples contain micropores in the amounts from 27 to $69 \mathrm{~mm}^{3}$ of liquid nitrogen $/ \mathrm{g}$, the highest being observed at ternary mixed oxides. Comparison of the $S_{\mathrm{BET}}$ and $S_{\text {meso }}$ surface areas reveals that about $30-40 \%$ of the surface comes from the surface of micropores. The ternary supports exhibit higher surface area $S_{\mathrm{BET}}$ than the binary and pure oxide [16] due to more amorphous structure. Substitution of titania by $31-36$ mol\% of zirconia in the TiAlZr-1 and TiAlZr-2 samples stabilizes their structure. Accordingly, their $S_{\mathrm{BET}}$ surface area is two times higher than that of the TiAl20 sample. Loading of the HPMo acid or its cobalt salt over all prepared supports caused the $S_{\mathrm{BET}}$ decrease of 15-30 relative \%, very likely, as the result of the deposition of active component blocked the pores. After impregnation of all supports with HPMo acid or its Co salt the volume of micropores decreased because of their filling by active phase. Not only volume of micropores decreased after loading the active phase over the supports, also the volumes of mesopores decreased, the change is not, however, so substantial. The change correlates with the filling of the support pores by the active phase.

HR-TEM micrographs of the TiAlZr-1 and TiAlZr-2 supports and corresponding catalysts (Fig. 4) taken at two magnifications were recorded in order to verify whether the samples were amorphous or microcrystalline.
The samples exhibit typical amorphous materials morphology where undefined faceted particles are evident. The ternary mixed oxides form segregated amorphous microdomains, as Ulín et al. reported [31]. Though some micro-segregation occurs the crystallization of the materials is limited because of strong interaction among the metals during the steps of hydrolysis and condensation. Overlapping of particles, as well as spaces among them can be

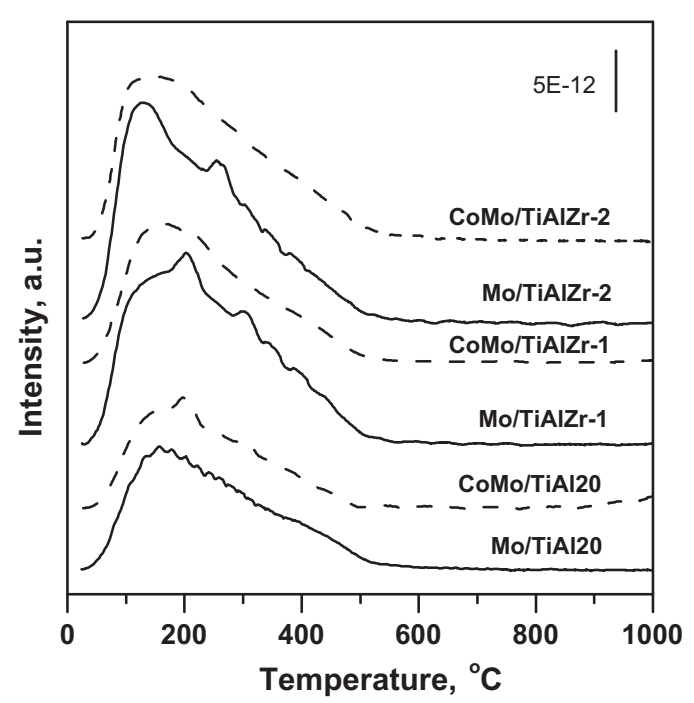

Fig. 5. TPD curves of ammonia adsorbed on the surface of the catalysts. 
observed. The TiAlZr-1 support is created from clusters of nanoparticles of the size of $10 \mathrm{~nm}$, which do show well-defined boundaries of a polygonal-like shape. The spaces among the particles form pores of various sizes. Loading of the Mo acid over the TiAlZr-1 support leads to a decrease in the particles diameter up to $5 \mathrm{~nm}$ and therefore, to a constriction of the free spaces forming pores. Diameter of the smallest pores varies from 3 to $7 \mathrm{~nm}$. Loading of CoMo compound over the support did not cause any substantial change in the morphology of the sample.

Majority of the TiAlZr-2 support particles seems to be separated and smaller than the particles in the TiAlZr-1 support. In some places of the Mo/TiAlZr-2 catalyst, a multilayer structure and aggregates of the particles of about $5 \mathrm{~nm}$ in diameter can be seen, however, the separated particles seem to be smaller than those in the support. Here the particles of the catalysts active phase are more clearly seen. In the CoMo/TiAlZr-2 catalyst, the particles of active phase are smaller than $\mathrm{Mo} / \mathrm{TiAlZr}-2$ catalyst. The layers forming both the support and active phase seem to be separated.

\subsection{Acidic properties and reducibility of the catalysts}

Acidity of both the supports and the catalysts were determined using temperature programmed desorption of ammonia. In order to overcome risk of molybdenum nitride formation we chose relatively high heating rate $\left(20^{\circ} \mathrm{C} / \mathrm{min}\right)$ during the TPD experiments. Using the procedure, determination of acidic properties in the temperature range of $30-500^{\circ} \mathrm{C}$ cannot be affected by formation of molybdenum nitride as it proceeds mainly under high reaction temperatures $\left(>700^{\circ} \mathrm{C}\right)$.

The example of the TPD curves of ammonia desorbed from the surface of the examined catalysts can be seen in Fig. 5. Ammonia desorption started at about $50^{\circ} \mathrm{C}$, it achieved the maximum of desorption rate very fast and then slowly decreased to zero at about $400-500{ }^{\circ} \mathrm{C}$. The maximum of desorption peak at about $130-170{ }^{\circ} \mathrm{C}$ was observed for all samples. The various amounts of alumina in the ternary supports did cause no considerable shift in desorption peak maximum. However, in the TPD- $\mathrm{NH}_{3}$ patterns the enlargement of the peaks in the direction of higher temperatures and a shoulder in this part of the desorption peak appears. The finding indicates that the catalysts comprise acidic sites of different strength - low, medium, and strong. A few clearly marked peaks were observed on the main curves of the ammonia desorption from Mo catalysts prepared on $\mathrm{Zr}$-containing supports. As a mass spectrometer was used for the identification of the desorption compounds (signal $m / e=16$ was collected), the peaks should belong to ammonia. The findings could be connected with the porous structure of the samples: three samples (Mo/TiZrAl-1, Mo/TiAlZr-2, and CoMo/TiAl20) which showed additional $\mathrm{NH}_{3}$ desorption peaks possess lower pore volume and smaller pore dimension than the other three samples (Mo/TiAl20, CoMo/TiZrAl-1 and Mo/TiAlZr-2). Alternatively, the additional peaks could be connected with the presence of different kinds of acid centers coming from different state of Mo-O bonds.

Quantitative data of the ammonia amount desorbed from the samples are given in Table 3. Acidity of the catalysts prepared over the supports containing zirconia or higher amount of alumina is significantly increased. Also acidity of the Mo catalysts prepared over TiAlZr-1 and TiAlZr-2 oxides is higher compared to that of the supports. When cobalt salt of heteropoly acid was loaded on the supports, the strength of acid sites and their amount increased only slightly.

Reducibility of the samples was measured using a hydrogen-nitrogen mixture $\left(10 \mathrm{~mol} \% \mathrm{H}_{2}\right.$ in $\left.\mathrm{N}_{2}\right)$. Heating rate applied in the experiments was sufficiently fast $\left(20^{\circ} \mathrm{C} / \mathrm{min}\right)$ in order to hinder formation of molybdenum nitride in the temperature range of $20-600^{\circ} \mathrm{C}$ which is important for the HDS catalytic

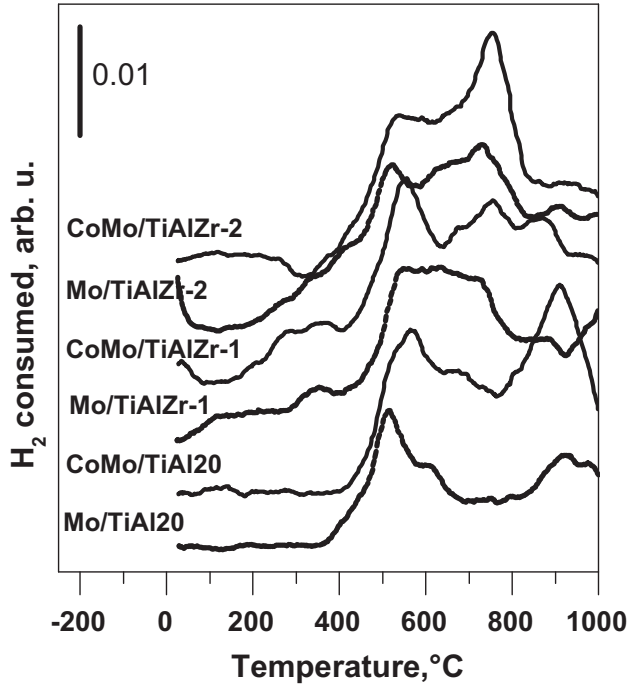

Fig. 6. TPR patterns of the catalysts.

reaction. (Formation of $\gamma-\mathrm{Mo}_{2} \mathrm{~N}$ usually proceeds at substantially lower heating rates $\left(0.6-2{ }^{\circ} \mathrm{C} / \mathrm{min}\right.$ [42].) Despite the limitation, the TPR experiments were carried out up to $1000^{\circ} \mathrm{C}$, in order to investigate the changes in the state of the catalyst components.

TPR curves of the catalysts examined in their oxide form are depicted in Fig. 6 and quantitative data obtained from their analysis are summarized in Table 4.

The TPR pattern of the Mo/TiAl20 catalyst shows two principal peaks at about $515^{\circ} \mathrm{C}$ and $920^{\circ} \mathrm{C}$. The first peak agrees well with that found by other researchers for $\mathrm{CoMo} / \mathrm{Al}_{2} \mathrm{O}_{3}$ catalysts [47] or CoMo/MCM-41 [48]. This peak is ascribed to reduction of octahedral $\mathrm{Mo}^{6+}$ species as well as to reduction of other phases (like $\mathrm{Mo}^{5+}$ and $\mathrm{Mo}^{4+}$ ) simultaneously formed during reduction of the oxide catalysts. The broad high-temperature peak at ca. $900{ }^{\circ} \mathrm{C}$ can be assigned to the dispersed, more refractory Mo species in tetrahedral coordination and/or to the subsequent reduction of the formed $\mathrm{Mo}^{4+}$ to $\mathrm{Mo}^{0}$. This peak was observed in case of alumina-magnesia and alumina-zirconia supported catalysts, in which the supports are relatively more basic than alumina-titania and pure alumina supports, and therefore, stronger interaction between support and active metals can be expected $[43,44]$. The TPR patterns of the Mo catalysts prepared over TiAlZr-1 and TiAlZr-2 supports leads to more dispersed molybdenum particles because of increased amorphization of the supports containing $\mathrm{ZrO}_{2}$, what reflects in the shift of reduction peaks maxima to lower temperatures. Various temperatures of the peaks maxima observed with the examined supported

Table 3

Amount of ammonia desorbed during TPD experiments within temperature range $25-500{ }^{\circ} \mathrm{C}$ from the investigated catalysts.

\begin{tabular}{llcl}
\hline Catalyst & $\mathrm{mmol} \mathrm{NH}_{3} \mathrm{~g}^{-1}$ & $\mu \mathrm{mol} \mathrm{NH}_{3} \mathrm{~m}^{-2}$ & $T_{\max }\left({ }^{\circ} \mathrm{C}\right)$ \\
\hline TiAl20 & 1.33 & 7.7 & 165 \\
Mo/TiAl20 & 1.22 & 8.8 & 161 \\
CoMo/TiAl20 & 1.57 & 13.0 & 158 \\
TiAlZr-1 & 1.33 & 8.9 & 129 \\
Mo/TiAlZr-1 & 2.12 & 16.7 & 164 \\
CoMo/TiAlZr-1 & 2.24 & 19.6 & 164 \\
TiAlZr-2 & 1.37 & 4.4 & 133 \\
Mo/TiAlZr-2 & 2.39 & 11.2 & 132 \\
CoMo/TiAlZr-2 & 2.25 & 10.0 & 132 \\
TiZr20 & 1.30 & 4.3 & 163 \\
Mo/TiZr20 & 1.20 & 4.7 & 162 \\
CoMo/TiZr20 & 1.55 & 6.8 & 154 \\
\hline
\end{tabular}


Table 4

Amounts of hydrogen consumed during TPR measurements and maxima of the reduction peaks.

\begin{tabular}{|c|c|c|c|c|c|}
\hline Catalyst & $\mathrm{mmolg}^{-1^{*}}$ & $T_{\max }\left({ }^{\circ} \mathrm{C}\right)$ & & & \\
\hline Mo/TiAl20 & 0.79 & & 513 & $612 \mathrm{sh}$ & 920 \\
\hline Mo/TiAlZr-1 & 0.77 & 345 & 550 & 719sh & $>1000$ \\
\hline Mo/TiAlZr-2 & 0.60 & & 522 & 733 & 910 \\
\hline CoMo/TiAl20 & 1.22 & & 570 & $677 \mathrm{sh}$ & 910 \\
\hline CoMo/TiAlZr-1 & 0.67 & 360 & 555 & 756 & 873 \\
\hline CoMo/TiAlZr-2 & 0.71 & & 532 & 756 & 920 \\
\hline
\end{tabular}

Temperature range $25-650^{\circ} \mathrm{C}$.

catalysts indicate that the support plays an important role in reduction of Mo species [8].

Incorporation of the Co salt of Mo heteropoly acid into the TiAl20 support increased peak intensities and shifted the first peak to higher temperature, very likely, due to formation of compounds that are reducible with more difficulty. In the presence of zirconium-containing supports cobalt effect on TPR curves could not be seen. Discussion of the TPR profiles obtained in the high temperature region (temperatures higher than $600^{\circ} \mathrm{C}$ ) is very complicated, as formation of various molybdenum compounds and cobalt molybdenum compounds, as well as molybdenum nitride is possible. However, this temperature range cannot be useful for catalyst characterization. In all cases, the TPR curves did not reach the baseline, either because of non-finished reduction of the components reduced with difficulties (such as aluminate $\mathrm{CoAl}_{2} \mathrm{O}_{4}$ ) or due to formation of molybdenum nitride at the high reaction temperatures.

It is also necessary to mention the unusual reduction course of the CoMo and Mo catalysts in the low temperature range $\left(50-400^{\circ} \mathrm{C}\right)$. In the case of the CoMo catalysts prepared over ternary mixed oxides, a broad peak observed in the region of $200-400^{\circ} \mathrm{C}$ could be ascribed to reduction of Co oxide species $[48,49]$. But this is not the case of Mo catalysts prepared over the same ternary supports. As the concentration of the consumed hydrogen was determined by a catharometer recording a change in thermal conductivity of a gas phase used during measurement, the peaks appearing in this region do not necessarily show consumption of hydrogen, but could also record formation of gases with low thermal conductivity, like hydrocarbons. Such gases could be formed from the organic compounds used during supports preparation, which were not completely removed in the step of the supports calcination (temperature $350^{\circ} \mathrm{C}$ was chosen because of preserving the structure of heteropoly acids compounds).

\subsection{Catalytic activity}

Conversions of thiophene to butane (HDS) obtained over the supported Mo heteropoly acid and its Co salt determined at $350^{\circ} \mathrm{C}$ is presented in Fig. 7.

It can be seen that the partial substitution of titania in the TiAl20 support by zirconia, accompanied by slight increase in alumina amount (16.4 instead of $13.5 \mathrm{~mol} \%$ ), increased slightly HDS of thiophene over the Mo catalyst. Such increase could be connected with amorphization of the support after addition of zirconia as well as with the increased ternary support acidity. However, though amount of alumina in the mixed TiAlZr-2 oxide, higher than that in the TiAlZr-1 support ( $39 \mathrm{~mol} \%$ vs. $16.4 \mathrm{~mol} \%$ ), caused significant increase in acidity (Table 3), HDS activity of the Mo/TiAlZr-2 catalyst decreased (thiophene conversion decreased two times). Very likely, other physical-chemical properties play a role. For example, $\mathrm{H}_{2}$ consumption $\left(25-600^{\circ} \mathrm{C}\right)$ observed with this sample is lower than that of the other prepared Mo catalysts (Mo/TiAl20 and $\mathrm{Mo} / \mathrm{TiAlZr}-1$ ). It could be deduced from the reduction peak temperatures referring to easiness of the active component reduction (Table 4 ) that the amount of easily reducible catalytic components

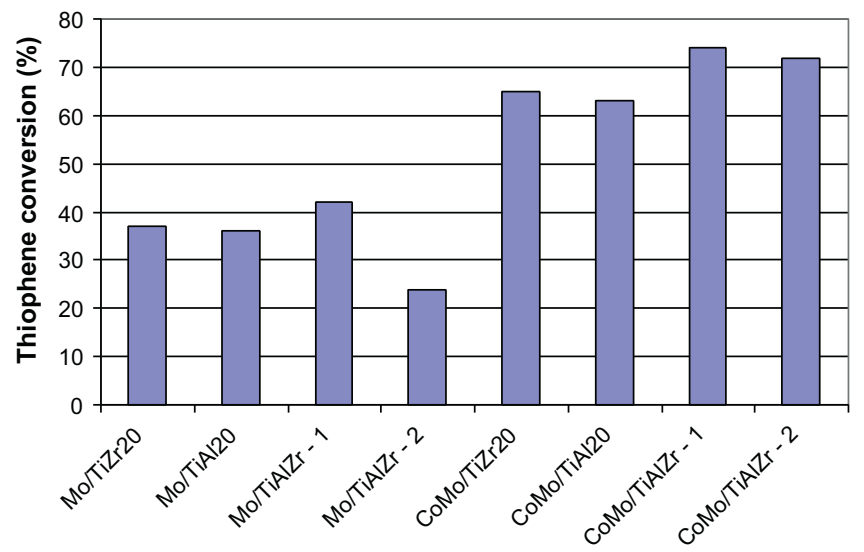

Fig. 7. Thiophene conversion over the Mo and CoMo catalysts supported on mixed Ti, Zr, Al oxides.

is very important for the HDS catalytic reaction. Formation of the aluminomolybdates in the Mo/TiAlZr-2 sample, reducible with difficulties could explain lower catalytic activity.

The maximum in thiophene conversion seems to be determined by the optimum content of alumina in the supports. More than twofold increase of alumina amount in the TiAlZr-2 sample (39 mol\% $\mathrm{Al}_{2} \mathrm{O}_{3}$ ) compared to the TiAlZr-1 sample $(16.4 \mathrm{~mol} \%$ $\mathrm{Al}_{2} \mathrm{O}_{3}$ ) led to the HDS activity decrease observed with the Mo loaded sample. This fact indicates that catalyst activity depends on the surface properties of the supports. Ramirez et al. [45] showed previously that two aluminum species are detected in the Mo catalysts, first one forming a part of the surface monolayer and the second octahedrally coordinated in the bulk. According to these authors, presence of the alumina monolayer in the mixed oxides supports can lead to higher interaction of molybdenum with alumina and to formation of alumina molybdate having lower activity in HDS. In the catalysts prepared by support impregnation with CoMo salt, the cobalt masks the effect of the support increasing activity of all samples. In this case, we can suggest interaction of cobalt ions with the support leading to a lower extent of the alumina molybdate formation.

\section{Conclusions}

Titania-alumina-zirconia mixed oxides have been prepared by partial substitution of $\mathrm{TiO}_{2}$ by other oxides using sol-gel synthesis. The effect of separated oxides on the state of the oxide structures has been investigated: zirconia stabilizes the anatase phase of $\mathrm{TiO}_{2}$, and both zirconia and alumina lead to the amorphization of mixed oxide and to decrease in the acid sites strength. No formation of new oxide phase has been revealed. Alumina forms a separated layer on the mixed oxides surface at the high content of alumina in the mixture. This layer interacts with the loaded catalyst components.

The observed catalytic properties of the ternary mixed oxides catalysts in HDS reaction seem to be related to the amorphous nature of the catalytic structure manifesting different surface areas 
and leading to high dispersion of the loaded compounds and consequently to higher number of active sites. The acidity of the catalysts prepared over the supports containing zirconia or higher amount of alumina significantly increases.

The maximum in HDS activity of catalysts has been observed in the case of optimum content of alumina in the mixed oxide supports. Incorporation of the cobalt heteropolyacid salt over the support affects the morphology of particles and dispersion of active centers. Raman spectra indicated bridged Mo-O-Mo bonds what is the proof of easier reducibility of the catalysts. In the presence of alumina, cobalt is a better promoter as it increases the catalyst activity about two times and complicates the effect of the support composition on the HDS activity.

\section{Acknowledgments}

This work was made with the financial support of the Bulgarian Ministry of Education, Fund "SCIENTIFIC RESERCH" (project no. DPOSTDOC 02/5-2010). E. K., A.S., K.J. highly acknowledges the Bulgarian and Czech Academies for Support of Scientific Cooperation.

TEM-EDS experimental data were provided by Centro Grandi Apparecchiature - UniNetLab - Università di Palermo funded by P.O.R. Sicilia 2000-2006, Misura 3.15 Azione C Quota Regionale.

\section{References}

[1] I.C. Leite Leocadio, S. Braun, M. Schmal, J. Catal. 223 (2004) 114-121.

[2] Y. Nguyen Huu Nhon, H. Mohamed Magan, C. Petit, Appl. Catal. B 49 (2004) 127-133.

[3] S. Andonova, Ch. Vladov, B. Pawelec, I. Shtereva, G. Tyuliev, S. Damyanova, L. Petrov, Appl. Catal. A 328 (2007) 201-209.

[4] V. Lochar, Appl. Catal. 309 (2006) 33-36.

[5] M.P. House, A.F. Carley, M. Bowker, J. Catal. 252 (2007) 88-96.

[6] H. Balcar, P. Topka, N. Ilkova, J. Perez-Pariente, J. Cejka, Stud. Surf. Sci. Catal. 156 (2005) 795-802.

[7] C.W. Bielawski, R.H. Grubbs, Prog. Polym. Sci. 32 (2007) 1-29.

[8] B.M. Reddy, B. Chowdhury, P.G. Smirniotis, Appl. Catal. A 211 (2001) 19-30.

[9] B. Solsona, A. Dejoz, T. Garcia, P. Concepción, J.M. Lopez Nieto, M.I. Vázquez, M.T. Navarro, Catal. Today 117 (2006) 228-233.

[10] H. Toraya, M. Yoshimura, S. Somiya, J. Am. Ceram. Soc. 67 (1984) C119-C121.

[11] S. Damyanova, A. Spojakina, K. Jiratova, Appl. Catal. A 25 (1995) 257-269.

[12] C. Pophal, F. Kameda, K. Hoshino, S. Yoshinaka, K. Segawa, Catal. Today 39 (1997) 21-32.

[13] S. Damyanova, P. Grange, B. Delmon, J. Catal. 168 (1997) 421-430.

[14] M.S. Rana, B.N. Srinivas, S.K. Maity, G. Murali Dhar, T.S.R. Prasada Rao, J. Catal. 195 (2000) 31-37.
[15] S.K. Maity, B.N. Srinivas, V.V.D.N. Prasad, A. Singh, G. Murali Dhar, T.S.R. Prasada Rao, in: T.S.R. Prasada Rao, G. Murali Dhar(Eds.) Stud. Surf. Sci. Catal. 113 (1998) 579.

[16] E. Kraleva, A. Spojakina, M.L. Saladino, S. Enzo, E. Caponetti, J. Struct. Chem. 52 (2011) 330-339.

[17] E. Kraleva, A. Spojakina, M.L. Saladino, E. Caponetti, K. Jiratova, J. Nanosci. Nanotechnol. 10 (2010) 1-7.

[18] J. Fung, I. Wang, J. Catal. 130 (1991) 577-587.

[19] H. Hattori, M. Itoh, K. Tanabe, J. Catal. 38 (1975) 172-178.

[20] H.J.M. Bosman, E.C. Kruissink, J.V. Spoel, F.V. Brink, J. Catal. 148 (1994) 660-672.

[21] A. Baiker, P. Dollenmeier, M. Glinski, A. Reller, Appl. Catal. 35 (1987) 365-380.

[22] G. Murali Dhar, B.N. Srinivas, M.S. Rana, M. Kumar, S.K. Maity, Catal. Today 86 (2003) 45-60.

[23] N. Takahashi, A. Suda, I. Hachisuka, M. Sugiura, H. Sobukawa, H. Shinjoh, Appl. Catal. B 72 (2006) 187-195.

[24] K. Ito, S. Kakino, K. Ikeue, M. Machida, Appl. Catal. B 74 (2007) 137-143.

[25] K.M. Adams, G.W. Graham, Appl. Catal. B 80 (2008) 343-352.

[26] H. Imagawa, T. Tanaka, N. Takahashi, Sh. Matsunaga, A. Suda, H. Shinjoh, Appl. Catal. B 86 (2009) 63-69.

[27] N. Takahashi, S. Matsunaga, T. Tanaka, H. Sobukawa, H. Shinjoh, Appl. Catal. B 77 (2007) 73-79.

[28] M.T. Pope, Heteropolyacid and Isopolyoxometellates, Springer-Verfag, Berlin, 1983.

[29] J. Yang, Y. Huang, J.M.F. Ferreira, J. Mater. Sci. Lett. 16 (1997) 1933-1935.

[30] A. Spojakina, E. Kraleva, K. Jiratova, L. Petrov, Appl. Catal. A 288 (2005) $10-17$.

[31] C.A. Ulín, J.A. DeLosReyes, J. Escobar, M.C. Barrera, M.A. Corteřs-Jacome, J. Phys. Chem. Solids 71 (2010) 1004-1012.

[32] J.M. Miller, L. Jhansi Lakshmi, J. Phys. Chem. B 102 (1998) 6465-6470.

[33] D. Carriazo, J. Solid State Chem. 181 (2008) 2046-2057.

[34] C. Rocchiccioli-Deltcheff, A. Aouissi, S. Launay, M. Fournier, J. Mol. Catal. A 114 (1996) 331-342.

[35] C. Rocchiccioli-Deltcheff, A. Aouissi, M.M. Bettahar, S. Launay, M. Fournier, J. Catal. 164 (1996) 16-27.

[36] G. Leofanti, M. Padovan, G. Tozzola, B. Venturelli, Catal. Today 41 (1998) 207-219.

[37] S.J. Gregg, K.S.W. Sing, Adsorption Surface Area and Porosity, Academic Press, New York, 1982.

[38] A. Lecloux, P. Pirard, J. Colloid Interface Sci. 70 (1979) 265-271.

[39] E.P. Barrett, L.G. Joyner, P.P. Halenda, J. Am. Chem. Soc. 73 (1951) 373-380.

[40] S. Brunauer, J. Skalny, E.E. Bodor, J. Colloid Interface Sci. 30 (1969) 546-552.

[41] P. Schneider, Appl. Catal. A 129 (1995) 157-165.

[42] S. Gong, H. Chen, W. Li, B. Li, Fuel Chem. Div. Preprints 8 (1) (2003) 191-192.

[43] J. Yang, J.M.F. Ferreirar, Mater. Lett. 36 (1998) 320-330.

[44] X.Z. Ding, X.H. Liu, Y.Z. He, J. Mater. Sci. Lett. 13 (1994) 462-464.

[45] J. Ramirez, G. Macías, L. Cedeño, A. Gutierrez-Alejandre, R. Cuevas, P. Castillo, Catal. Today 98 (2004) 19-30.

[47] P. Arnoldy, M.C. Franken, B. Scheffer, J.A. Moulijn, J. Catal. 96 (1985) 381.

[48] J. Ramirez, R. Contreras, P. Castillo, T. Klimova, R. Zárate, R. Luna, Appl. Catal. A 197 (2000) 69-78.

[49] S. Todorova, H. Kolev, J.P. Holgado, G. Kadinov, Ch. Bonev, R. Pereníguez, A. Caballero, Appl. Catal. B 94 (2010) 46-54. 